\title{
A Comparison of Different Reconstruction Modes and Adaptive Evaluation Systems for Community Recovery Following the Wenchuan Earthquake
}

\author{
Mingming Xiang ${ }^{1,2}{ }^{\mathbb{D}}$, Wei Zhao ${ }^{1, *}$ and Jiao Chen $^{3}$ \\ 1 College of Architecture and Environment, Sichuan University, No.24 South Section 1, Yihuan Road, \\ Chengdu 610065, Sichuan Province, China; mingmingxiang@hotmail.com \\ 2 School of Civil Engineer and Architecture, Southwest University of Science and Technology, \\ No. 59 Qinlong Avenue, Mianyang 621010, Sichuan Province, China \\ 3 School of Architecture and Design, Southwest Jiaotong University, No.111 North Section 1, Erhuan Road, \\ Chengdu 610031, Sichuan Province, China; chenjiao@swjtu.edu.cn \\ * Correspondence: zw@home.swjtu.edu.cn; Tel.: +86-138-0808-9279
}

Received: 6 October 2018; Accepted: 5 November 2018; Published: 9 November 2018

\begin{abstract}
Living environment reconstruction in Wenchuan earthquake disaster-hit areas received substantial attention internationally, so it is imperative to examine out the methods employed, to evaluate community reconstruction and recovery performances. However, the existing evaluation systems for post-disaster reconstruction practices are mostly generalized models, and thus, the actual differences among various reconstruction modes and local characteristics are given insufficient attention. After 10 years of reconstruction and recovery, Dujiangyan, Beichuan, and Wenchuan have exhibited distinct differences and characteristics because of two different reconstruction modes: "paired assistance" and "self-construction". Based on a thorough review of the literature and expert judgments, this article focuses on the introduction of evaluation factors comprising the opinions and requirements of disaster victims. Adopting the "four-step method" to select the evaluation factors through conceptual consolidation, analytical structuring, indicator identification, and index creation, this article summarizes the homogeneities and heterogeneities of the three different areas. The results reveal that people in different areas under the influences of different reconstruction modes and local characteristics will emphasize different evaluation factors and demonstrate different levels of concern for the same factor. This article analyzes the three areas and establishes an adaptable evaluation index system to provide scientific guidance to community recovery evaluations in different areas after major disasters.
\end{abstract}

Keywords: community recovery; living environment reconstruction; paired assistance; built environment evaluation; evaluation index system

\section{Introduction}

At present, the impacts of natural disasters on the world are continuing to increase steadily. Tens of thousands of people are killed each year as a result of natural disasters, while millions more are injured or displaced. Meanwhile, the property damage generated by such disasters has doubled every seven years over the past 40 years. According to statistics from the International Council of Scientific Unions (ICSU), the recorded frequency of disasters was 100 times per decade from 1900 to 1940. By the 1960s and 1980s, this figure had increased to 650 times per decade and 2000 times per decade, respectively, and this number jumped to approximately 2800 times per decade by the 1990s. Natural disasters occur frequently throughout the world, such as the 2011 East Japan earthquake, the 2015 Nepal earthquake, the 2017 U.S. hurricane, and the 2018 Indonesian tsunami, etc. In order to 
reduce disaster risk, it is necessary to overcome existing difficulties and to prepare for future challenges. The United Nations International Strategy for Disaster Reduction (UNISDR) advocates: monitoring, assessing and understanding disaster risk, and sharing this information; strengthening disaster risk management and coordinating related agencies and departments so that relevant stakeholders can completely and effectively participate in the work at appropriate levels; enhancing early warning systems, preparedness, response, recovery, rehabilitation, and reconstruction for multiple disasters [1]. Against this international background, tracking, evaluation, and establishment of a database of the practical effects of post-disaster reconstruction become particularly important. Accordingly, the academic community is increasingly researching disaster recovery programs $[2,3]$.

Statistical data reveal an increase in the number of transdisciplinary research projects, particularly those dealing with the impacts of natural disasters on cities and urban regions $[4,5]$. These research makes it attractive to approach such questions in an integrative manner. Additionally, long-term climate change processes are not only relevant to urban and regional development, but also surprisingly related to the development of natural hazards in the short term [6]. Many previous studies focus on either a specific type of hazard, such as earthquakes, floods, and hurricanes [7,8], or a comprehensive set of disasters, primarily with regard to their specific impacts $[9,10]$. Some have mixed mathematical principle-based methodologies for selecting the location of temporary shelter sites [11]. Many of these publications that dealt with different reconstruction and recovery processes in urban regions either examined one specific conceptual approach to address the impacts of such disaster [12,13], or limited their focus to specific disciplines in the practical realm, such as risk assessment [14] and recovery assessment [15,16]. In 2012, UNISDR proposed the Global Programme Action of "Making Cities More Resilient", which said that in the case of natural hazard factors that are difficult to control, the most direct and effective way to reduce disaster risk and impact was to improve the resilience of hazard bearing body [17].

It is highly important to evaluate post-disaster recovery processes to review the effects of completed reconstruction efforts and predict the land-use and infrastructure layout plans for the future. Several qualitative and quantitative approaches have been used to evaluate post-disaster recovery processes $[18,19]$. The literature in this area has focused on several topics ranging from post-disaster housing recovery $[20,21]$ to the reconstruction of property rights $[22,23]$, and it has concentrated on different thematic areas, including urban planning [6,24], capacity reconstruction [25], and environmental perspectives [26]. Many of these studies have suggested that urgency and uncertainty in post-disaster recovery practices lead to short-term decisions that do not address (and may even amplify) pre-disaster social, economic, and environmental weaknesses [14]. Thus, these weaknesses are likely to emerge over a long period, and they may have a lasting impact on both the society and economy. The cultural dimension had been neglected for a long time, but since the "Hyogo framework for action 2005-2015" [27], and the "Sendai framework for disaster risk reduction 2015-2030" [1], there has been significant progress in the field of research on cultural reconstruction and protection of national culture, etc.

Following the destruction of the 1976 Tangshan earthquake and other natural disasters, and in the wake of complex social problems such as reservoir resettlement, China has started research on natural disasters and post-disaster reconstruction practices. However, there have not been many academic breakthroughs in this field. The 2008 Wenchuan earthquake reinvigorated many domestic scholars to research natural disasters [28,29]. The subsequent literature concerns policies, laws, and regulations, theories, ideas, and other aspects of that research [30,31]. In connection with the problems associated with urban and rural post-disaster reconstruction planning, policies, and measures, Qiu [28] proposed that the people should choose technological innovations, employment opportunities, and living situations, as well as post-disaster evolution, reconstruction, and transformation practices and other eco-city construction modes should be made on the basis of actual situations in seismic areas. Qiu further advocated that such decisions should be made by combining the advice of experts with public participation to promote community recovery [32]. 
Wenchuan was widely and severely affected by the 2008 earthquake, and thus it was difficult to achieve reconstruction while relying solely on the government. To an extent, the reconstruction was conducted through a market approach. The country's top-down political system mandates provincial and local governments from more economically developed regions to assist devastated areas with post-disaster reconstruction. Leaders from donor regions have strong incentives to accomplish assigned reconstruction tasks because of the practices of local accountability [33]. Below "paired assistance" ("Paired assistance" refers to a program launched by the Chinese government after the Wenchuan earthquake. In this program, each county affected by the earthquake was paired with a province by the central government. The provinces provided direct support to the affected counties during the recovery process.) and "self-construction", central government, local government, assistance government, experts, and victims had their role in this sector and been allocated their rights, obligations, and interests to the political, planning, provision, and customer service levels. Zhao [23] noted that an excellent system design and a post-disaster property reconstruction plan are likely far more critical than material construction. During post-disaster city planning, material planning efforts should be planned far in advance; more importantly, however, local social culture should be restored through the design of the system. By examining the reconstruction of the earthquake-affected areas throughout Wenchuan, Zhao, and Yang [34] argued that some built environment evaluation methods could not adapt to individual cases of post-disaster rehabilitation and reconstruction. The process through which the associated evaluation factors are determined must be updated. In an actual disaster situation, different conclusions can be drawn from generalized built environment evaluation factors, based on the analysis and sorting of different variables. A determination of the disaster-related variables and an analysis of their interrelationships could reveal the vital characteristic factors for conducting an evaluation of the built environment in seismic areas.

It is necessary to learn from related research; however, an updated evaluation index system should be created particularly because of the Wenchuan earthquake. The Chinese government summed up the characteristics of those seismic areas as: (a) the topography was complex, (b) natural disasters happened frequently, (c) the ecological environment was fragile, (d) "paired assistance" and "self-construction" co-existed, (e) the economic foundation was weak, and (f) ethnic minorities inhabited it. This article tries to solve the main problem of the lack of an appropriate set of criteria that are both measurable and fundamental to apply across different places. In addition, through a case analysis focused on the combination of the "paired assistance" and "self-construction" concepts used in Dujiangyan [31], this article also suggests that post-disaster reconstruction evaluative criteria can be useful only if they are incorporated into a locally accountable (i.e., involving public participation) process of decision-making that includes a system of feedback and adjustment of planning priorities and approaches.

To sum up, on the one hand, disasters seriously impede the process of realizing sustainable development, and many have become more severe due to climate change increasing their frequency and intensity. It is imperative to anticipate, plan for, and reduce disaster risks in order to strengthen the resilience of individuals, communities, and countries, and their livelihoods, health, cultural heritage, socioeconomic assets, and ecosystems, more effectively. On the other hand, through the international decade for natural disaster reduction and the subsequent international strategy for disaster reduction, the international community has gained considerable experience in disaster risk reduction. There is a need to continue to strengthen good governance, and to improve disaster preparedness and coordination among countries in disaster response, recovery, and reconstruction at the national, regional, and global levels in disaster reduction strategies. Moreover, post-disaster recovery and reconstruction is used to make disaster areas "Build Back Better" with the support of a strengthened model of international cooperation. Therefore, the purpose of this article is to study three representative urban areas in the Wenchuan earthquake area and summarize the similarities, differences, and experiences after 10 years of development. 


\section{Materials and Methods}

\subsection{Definition}

An evaluation refers to a process of delineating, obtaining, and providing descriptive and judgmental information to guide decision-making, meet performance responsibilities, and promote the understanding of research subjects $[35,36]$. An evaluation is essentially a series of measurements that, based on individual research methods and techniques, can be compared with an index system [37], and it constitutes the subjective judgment of the valued relationship between an object and the subject's demand. Therefore, the post-disaster reconstruction of a living environment requires an examination of the value of the living environment; that is, the value of the relationship between the living environment and the needs of the victims. This is the main reason that the needs of the victims must be included in the construction of an evaluation factor set [38].

In the field of disaster prevention, the time periods after a natural disaster are generally divided into four phases: the normal phase, the disaster phase, the reconstruction phase, and the rehabilitation phase. Each phase has a different work focus, that is, emergency management, emergency response, recovery efficiency, and capacity development, respectively. These four phases represent a cycle that encompasses the entire lifecycle of environmental development [39,40]. However, this cycle does not describe a simple restoration process, but rather a growth-type evolutionary succession. After each reconstruction and recovery phase, the disaster prevention capabilities of hazard-affected objects should be improved; this enhancement also represents an essential attribute of disaster resilience (Figure 1). Meanwhile, throughout the life-cycle of environmental development, an evaluation can be performed at any stage. For example, a risk evaluation can be performed in regular time, a rapid evaluation can be conducted after a disaster has occurred, and an evaluation can be employed with regard to the effects of post-disaster reconstruction, and a resilience evaluation can occur during the recovery phase. This article focuses on an evaluation of the reconstruction of the post-disaster living environment, based on the needs of the disaster victims. The different ages and the economic, social, and cultural backgrounds of the evaluation subjects should be understood to ensure the appropriate selection of evaluation factors and the effective operability of the established evaluation system [3].

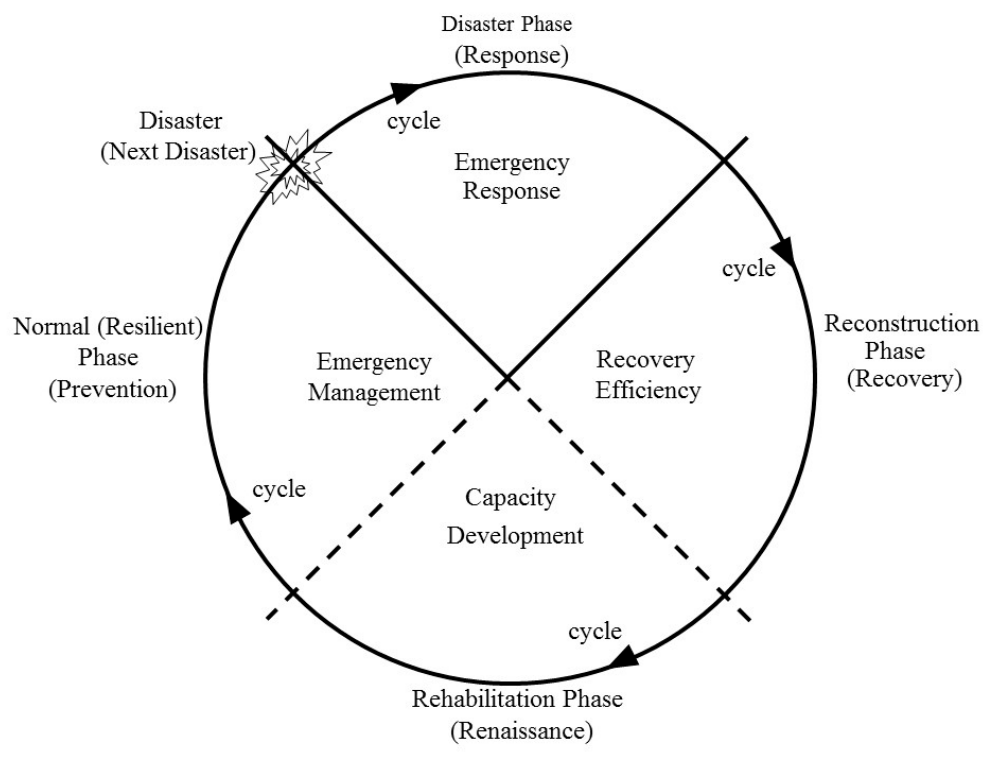

Figure 1. Schematic diagram of a disaster cycle model.

\subsection{Literature Survey}

Dozens of synthetic evaluation methods have been developed to date $[41,42]$. These methods all have different mathematical formulae, and their data requirements and effects are also unique to 
each approach. However, not all of the necessary knowledge is derived from data and principles. It is impossible to utilize a single method for all possible conditions, or to emphasize a single mathematical method. Therefore, choosing the proper method is a fundamental problem [7,10]. It is necessary to analyze the characteristics, commonalities, advantages, and disadvantages of various methods to correctly understand the substantive contents of those methods, and to select an appropriate evaluation approach.

It is also necessary to analyze the type of phenomenon and its internal structural relationships to select the appropriate evaluation method. In a practical problem, the evaluated object may have many uncertainties that present not only as singular uncertainties, but also as several combinations of uncertainty phenomena [16]. Such problems are more complicated, so it is necessary to choose a specific evaluation method in accordance with the dominant phenomenon $[18,19,43,44]$.

From the above descriptions (Table 1), it can be seen that the existing evaluation index systems for post-disaster reconstruction practices and disaster prevention management assign great importance to disaster prevention and reduction, as well as a community organization. However, the existing evaluation index systems for living environments and residential area renewal are relatively lacking in disaster prevention and reduction measures, and some focus only on the most basic evaluations of public security situations. Therefore, the selection of the evaluation factors in this study should supplement and refine the existing reference index systems.

Table 1. Structural comparison of typical domestic and foreign built environment evaluation index systems.

\begin{tabular}{|c|c|}
\hline Index System & Structure \\
\hline $\begin{array}{l}\text { The Great Hanshin earthquake disaster } \\
\text { recovery planning evaluation index system. }\end{array}$ & $\begin{array}{l}\text { Five criteria (welfare and housing, life and culture, industry employment, disaster } \\
\text { prevention, and region) and } 26 \text { indicators (Source: Government Network of Hyogo } \\
\text { prefecture, Japan. http:/ / web.pref.hyogo.jp/) }[27,45] \text {. }\end{array}$ \\
\hline $\begin{array}{l}\text { The comprehensive evaluation index system } \\
\text { of urban disaster reduction management. }\end{array}$ & $\begin{array}{l}\text { Three factor sets (disaster risk, vulnerability, and disaster-bearing capacity) and } \\
22 \text { indicators [46]. }\end{array}$ \\
\hline $\begin{array}{l}\text { The government emergency capability } \\
\text { evaluation index system. }\end{array}$ & $\begin{array}{l}\text { Six criteria (emergency response capability, information collection capability, } \\
\text { emergency rescue capability, resource integration capability, stability maintenance } \\
\text { ability, and post-disaster processing capacity), and } 25 \text { indicators [47]. }\end{array}$ \\
\hline $\begin{array}{l}\text { The evaluation index system of the } \\
\text { earthquake emergency response capacity in } \\
\text { urban communities. }\end{array}$ & $\begin{array}{l}\text { Five criteria (emergency response capability of community organizations, emergency } \\
\text { response capacity of community members, project earthquake resistance of the } \\
\text { community, community emergency preparedness capability, and community } \\
\text { emergency rescue capability) and } 23 \text { indicators [48]. }\end{array}$ \\
\hline $\begin{array}{l}\text { The sustainable development evaluation } \\
\text { index system of urban human settlements. }\end{array}$ & $\begin{array}{l}\text { Three aspects (living conditions, concentration of construction and sustainability), } \\
\text { six standards and } 30 \text { indicators [49]. }\end{array}$ \\
\hline $\begin{array}{l}\text { The evaluation index system of urban } \\
\text { human settlements. }\end{array}$ & $\begin{array}{l}\text { Ranges from the microscopic to macroscopic scale with three aspects (proximities to } \\
\text { the living environment, community environment, and urban environment), eight } \\
\text { standards, } 29 \text { indicators [50]. }\end{array}$ \\
\hline $\begin{array}{l}\text { The evaluation index system of residential } \\
\text { area planning in old districts. }\end{array}$ & $\begin{array}{l}\text { Four criteria (social benefits, environmental benefits, economic benefits, and emotional } \\
\text { utility) and } 34 \text { indicators [51]. }\end{array}$ \\
\hline $\begin{array}{l}\text { The evaluation index system after } \\
\text { residential area planning. }\end{array}$ & $\begin{array}{l}\text { Seven criteria (planning layout, spatial organization, relationships between the urban } \\
\text { landscape and historical features, residential interior landscape, resident groups, public } \\
\text { services and supporting facilities, and road traffic organization) and } 35 \text { indicators [ } 52 \text {. }\end{array}$ \\
\hline
\end{tabular}

Take the living environments of the cities and towns throughout the Wenchuan earthquake-stricken areas as an example. These areas are characterized by a complex topography and geomorphology, a high frequency of natural disasters, a fragile ecological environment, a multitude of critical ecological functions, an abundance of resources, a weak economic foundation, a high concentration of ethnic minorities, a society consisting of multicultural coexistence, and a plethora of unique historical and cultural resources. The national government mobilized the entire nation's power to assist in the reconstruction following the Wenchuan earthquake, and forced many of the economically developed cities to provide "paired assistance" to the earthquake-affected areas. This participation in the reconstruction enhanced the awareness and behaviors of people within the disaster-stricken areas. "Paired assistance" and public participation mechanisms became characteristic of the post-disaster reconstruction. Therefore, an extraction of the characteristics of the living environment for evaluation 
involves many aspects such as the ecological environment, national culture, history, and local culture, geographical features, economic recovery, and availability of paired assistance and public participation.

In summary, the scope of a disaster area may be extensive, the situation may be complicated, and the relationships of various evaluation elements may be in a disconnected state; however, all of these factors are interrelated. Therefore, to select the appropriate evaluation factors, the framework of an evaluation index system must be both neat and balanced. An ordered and scientific factor set will contribute to the use of a more concise, clear, and operable evaluation method.

\subsection{Methods}

The problems associated with post-disaster reconstruction practices are both numerous and complicated. Research scholars often use a multivariate analysis technique [36] with multiple evaluation factors that reflect the fundamental problems to understand the problems associated with urban development, realize the requirements for sustainable development, and combine integrated indicator surveys, expert interviews, and questionnaires (in Supplementary Materials) to select a factor set [45]. This study adopts the four-step method proposed by Coombes and Wong [53] to select evaluation factors through conceptual consolidation, analytical structuring, indicator identification, and index creation. This method, which has been widely cited and validated in multiple interdisciplinary fields, including urban-rural planning, social policy, and regional economics, guides the selection of the evaluation factors in an orderly and logical way, and each step has its own methodological support.

\section{Step 1: Conceptual Consolidation}

The basic concepts represented in the analysis were first clarified. By analyzing the evaluation goal, the basic concept of performance was clearly defined. To establish a conceptual structure based on empirical findings, this process usually began in a context of terminological uncertainty, that is, there were likely uncertainties that involved in naming the evaluation factors. In addition, case studies should be carried out to introduce the selection of evaluation factors into a practical and critical field. Based on this point of view, this study divided the affected areas into three representative samples and explored critical issues in each area.

\section{Step 2: Analytical Structuring}

A structure within which the indicators could be collated was provided. The purpose of this research was to (a) determine the problems that must be solved by policymakers during the post-disaster reconstruction efforts, and those that most concern the people within disaster-stricken areas and (b) select or create the evaluation factors that were most closely related to these critical issues. This step led to the emergence of both "top-down" and "bottom-up" approaches for determining the relevant evaluation factors. From the "top-down" perspective, the key problems that reflected the potential of post-disaster reconstruction efforts of a living environment were analyzed and summarized. The "bottom-up" approach was then employed to understand the core issues regarding people's understanding of disaster areas.

Step 3: Indicator Identification

The structure developed in Step 2 was translated into specific, measurable indicators. There was a large variety of possible evaluation factors for the most critical issues, all of which may be considered as potentially relevant. Therefore, the selected evaluation factor must be capable of evaluating the following attributes of each potential indicator: data availability, geographical specification, timing prospects, implementation, and interpretability. Coombes and Wong [53] believed that selection of the most appropriate evaluation factors was divided into two parts. First, the potential evaluation factors must be identified from a review of the literature. Second, the opinions of reputable experts on the evaluation factors must be collected. Wollebæk and Selle [54] considered that it could be divided into 
public, experts, and affected people in public participation, and that the impact of participation could be examined using three dimensions: intensity (active vs. passive participation), scope (many vs. few affiliations) and type (nonpolitical vs. political purpose). In this study, a third part (victim cognition), which is composed of feedback from the people within disaster-stricken areas, was introduced to directly and accurately reflect their opinions on the evaluation subjects (Figure 2).

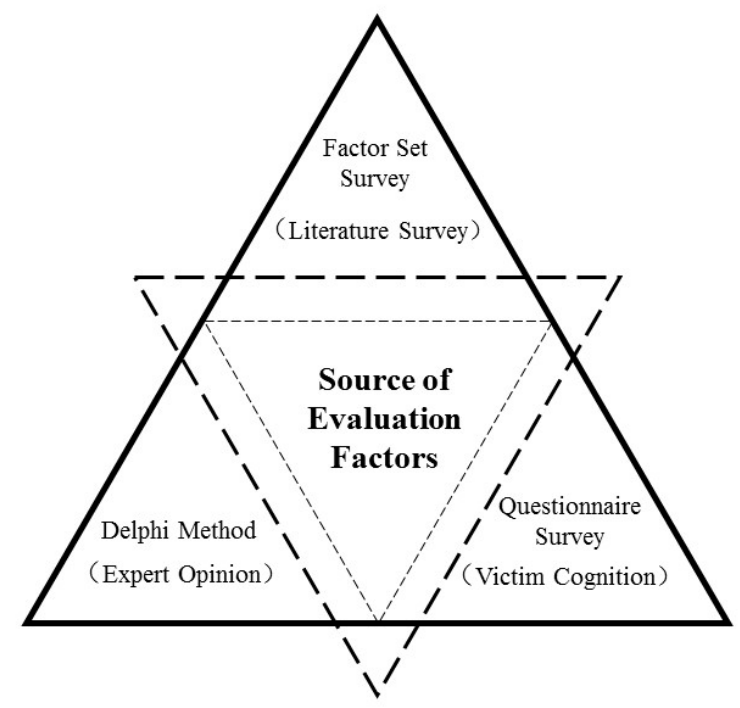

Figure 2. Comprehensive evaluation method in triangular form.

Step 4: Index Creation

The proposed indicators were synthesized into a single/composite measure. The biggest challenge of this process was the selection of appropriate mathematical analysis methods to merge a multitude of factors. This study used factor analysis of the more complex evaluation factors to reduce the dimensionality of the problem, thereby reducing it to an evaluation factor set that was relatively simple and operable.

\section{Study Sample Selection}

With multi-party cooperation, the State Council conducted the overall deployment of the post-disaster reconstruction following the Wenchuan earthquake, and characterized the disaster area as having a complex topography, a high frequency of natural disasters, a fragile ecological environment, a multitude of critical ecological functions, an abundance of resources, a weak economic foundation, and a society comprised of cohabitating ethnic minorities. This article selected Dujiangyan City, Yongchang Town in Beichuan County, and Weizhou Town in Wenchuan County as the study samples because of their statistical significance and unique characteristics [6].

\subsection{Reconstruction in Dujiangyan}

Dujiangyan was selected for research because of the following two reasons. First, the area was one of the most heavily damaged during the Wenchuan earthquake, and Dujiangyan almost certainly required the most reconstruction work among all of the affected areas. The houses of 108,900 families (more than 0.3 million individuals) were damaged to different degrees; 33,980 houses (Figure 3a) had to be rebuilt (Source: Dujiangyan People's Government Network. http:/ /www.djy. gov.cn). Second, the reconstruction of Dujiangyan was the most complex, as it involved concerted construction efforts of the local government and individual residents, with the paired assistance of Shanghai. Moreover, as many as seven types of construction methods were utilized after the earthquake, including government subsidies for housing repair and reinforcement, replacement 
housing, building houses on the original foundations, building houses at substitute locations, monetary compensation, unit-organized building, and off-site reconstruction [31]. In addition, the victims also played a prominent part in the reconstruction of the city of Dujiangyan.

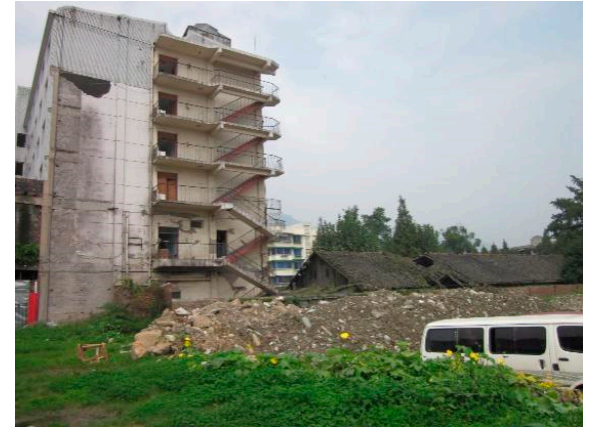

(a)

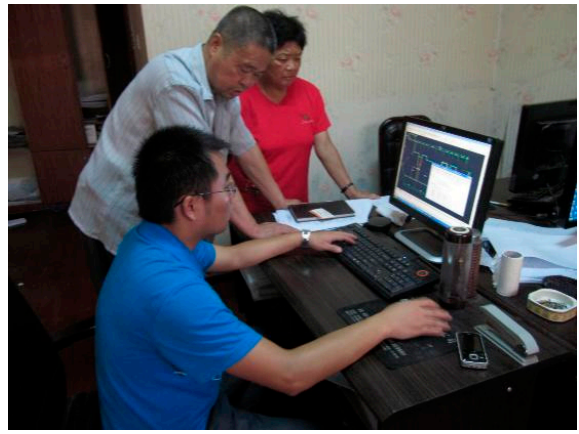

(b)

Figure 3. Investigation in Dujiangyan. (a) Houses after the earthquake; (b) Residents participating in designing their own houses.

The scope and extent of the earthquake-affected areas in Dujiangyan and the basic situation of the disaster characteristics therein were thoroughly understood, following a field investigation and data acquisition. This information helped us to understand the planning and implementation of post-disaster reconstruction practices and to become familiar with the organizational units, construction procedures, approval process, and resettlement distribution. Consequently, it is evident that Dujiangyan exhibited the following two features.

First, under a post-disaster reconstruction organization system led by the government with the participation of all available people, Dujiangyan fully reflects the entire process of the implementation of government policies. The departments of the central government, including the State Council and its subordinate civil affairs, in addition to the construction, government finance, finance, and industry sectors and other departments were all responsible for the formulation and implementation of various policies and laws related to post-disaster reconstruction, thereby providing both financial and policy support [38]. The local government led and coordinated various social forces to participate in the reconstruction. In addition, governments and organizations linked to the area through paired assistance actively played individual roles, making breakthroughs in the speed, quality, and level of reconstruction, which were widely praised by the central leadership and the victims.

Second, during the process of reconstruction, the people's opinion was fully respected; moreover, Dujiangyan actively guaranteed public participation. Approximately $20 \%$ of the 33,980 affected households freely chose different types of self-reconstruction, followed specific procedures, and directly expressed their wishes through community consultation platforms and participating in associated activities, e.g., architectural design (Figure 3b). The joint working group composed of government representatives and experts, including a comprehensive and meticulous community consultation platform to communicate with the affected people adequately; it also adjusted policies timely and coordinated various interests throughout all aspects of the reconstruction efforts, thereby satisfying the needs of residents during the reconstruction work. In addition, although they did not give up their rights to public participation, $80 \%$ of the affected households chose replacement housing. The victims' initiative and enthusiasm were reflected throughout the reconstruction process from the planning to the implementation and supervision of the settlement of the policy to the lottery process [23]. Public participation in Dujiangyan was much broader and involved than that which preceding new urban planning and urban renewal practices. 


\subsection{Reconstruction in Beichuan}

Yongchang Town in Beichuan was selected as the research object for the following three reasons. First, Beichuan Old Town was the only town that had its population relocated to Yongchang in its entirety after the Wenchuan earthquake; as a consequence, its production, and living and ecological conditions have attracted a great deal of attention. Second, as it was substantially destroyed, Beichuan was the most severely stricken county during the Wenchuan earthquake. According to the degree of damage, seismic areas were divided into four types according to various statistical data from the national "Wenchuan Earthquake Disaster Area Assessment": severely hit areas, ordinary areas, lightly hit areas, and influenced areas (Source: Beichuan Qiang Autonomous County People's Government Network. http://www.beichuan.gov.cn/). Beichuan was classified as a severely hit area. Third, Beichuan Qiang Autonomous County was the only county in China with distinct ethnic characteristics (Figure 4a).

Beichuan Old Town suffered substantial damage during the Wenchuan earthquake, and its population was thus relocated during the reconstruction efforts. The original site was transformed into the National Earthquake Ruins Museum, which has become a focus of international attention. The new county seat of Yongchang Town is a new gateway to Beichuan, whose spatial structure, urban characteristics, development scale, and functional localization have been significantly adjusted (Figure 4b).

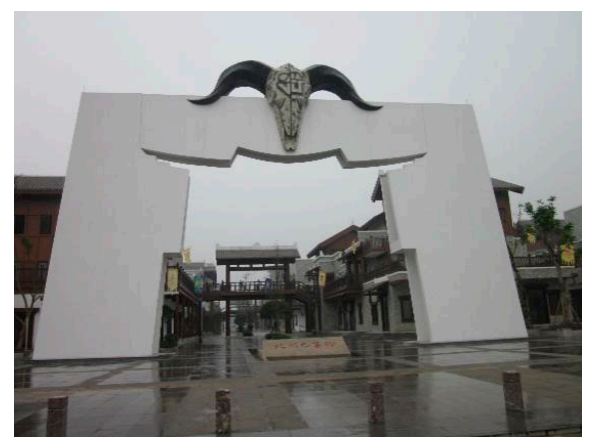

(a)

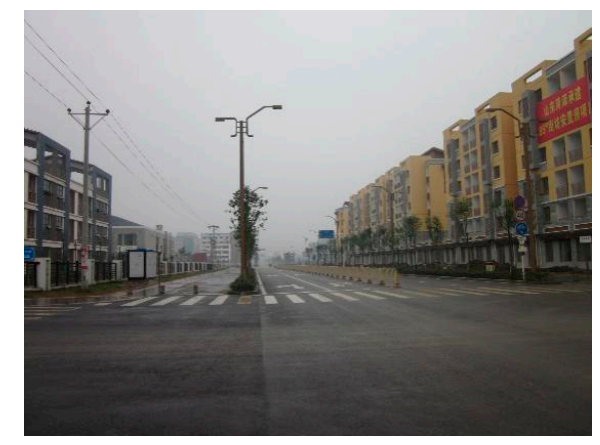

(b)

Figure 4. Investigation in New Beichuan County. (a) Public space with Qiang ethnic characteristics; (b) A residential building area.

The reconstruction of the new Beichuan County was an arduous system-wide task that consumed the most production factors, required the most time, and encountered the most challenges [55]. Therefore, a specific relationship required attention during the reconstruction planning; namely, the relationship between aid-building and self-building. Although time was scarce and the work tasks were arduous and complex, the requirements for the reconstruction of the new Beichuan County from the higher authorities were strict, and the expectations of the masses were great; thus, the "aid-building to drive self-building, self-building to drive joint-building" method was adopted [20,24]. However, the implementation of paired assistance could not avoid similar challenges, since the public participation was not sufficient, and the exchange of information was not equal.

\subsection{Reconstruction in Wenchuan}

Weizhou Town in Wenchuan was selected as a research object because of the following three reasons. First, Wenchuan was located in the mountains, with characteristically representative geologically and ecologically vulnerable seismic areas that lacked resources. Second, although Weizhou was located within the severely hit area, the town was affected relatively little, and urban social life quickly returned to normal. Consequently, interviews with the victims and questionnaire responses were readily available. Third, the town of Weizhou is relatively small in scale, and thus, representative data could be obtained more easily. 
In accordance with the unified deployment of governmental agencies, the Guangzhou government was paired to assist Weizhou Town, which is the county seat of Wenchuan County, during the post-disaster reconstruction. Following the Wenchuan earthquake, 131 people were pronounced dead, 42 people were established as missing, and 7129 people were injured. Approximately $80 \%$ of the buildings suffered immense damage; the vast majority of rural residential buildings collapsed, and most of the rural architecture was destroyed. Meanwhile, there was little damage to construction land in Weizhou, but 154.7 hectares of arable land were lost. The infrastructure was severely damaged; 17 kilometers of county municipal roads were left in ruins, and village roads were severely damaged. County municipal facilities were all destroyed, the pipe systems were severely damaged, and the basic facilities in the villages were utterly ruined. Thus, the post-disaster reconstruction was a very arduous task (Source: Wenchuan People's Government Network. http://www.wenchuan.gov.cn/).

Although the urban area of Weizhou has been fundamentally improved due to Guangzhou's aid efforts, the city continues challenges to face changes that cannot be controlled due to difficulties associated with operations, maintenance and, development that influence the direction of the city's development. First, with the continuous development of the city and changes to the city's industries, the existing city scale cannot meet the needs of future development, and thus, the city's spatial structure must change. Second, with the withdrawal of aid teams and capital, the planning management and construction of the city will decline to some degree. Third, its valley location remains vulnerable to natural disasters after an earthquake, e.g., landslides and flooding (Figure 5).

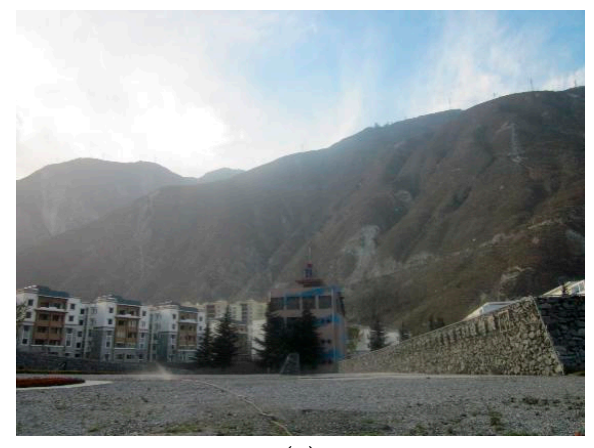

(a)

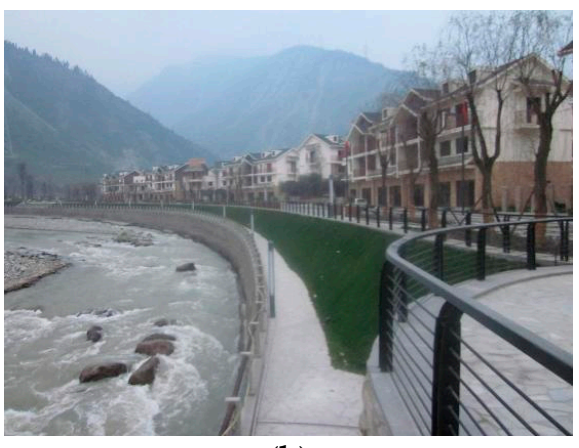

(b)

Figure 5. Investigation in the town of Weizhou of Wenchuan County. (a) Landslide hazard after the earthquake; (b) Reconstruction with potential risks.

From the above analysis, the three disaster-stricken area samples have common evaluation factors such as living environments, restoration, and reconstruction efforts, cultural development, and disaster prevention measures. They also exhibit different evaluation factors, such as the public participation characteristics of Dujiangyan, the paired assistance of Beichuan, and the ecological carrying capacity of Wenchuan. In addition, the same evaluation factor concept, namely, the national culture, has different characteristics among the three disaster areas, as it reflects the uniqueness of Beichuan while reflecting integration and inclusion in Wenchuan.

\section{Construction of Evaluation Factors}

\subsection{Conceptual Consolidation}

The basic concept of a community recovery evaluation can be obtained from the general characteristics of the seismic areas, the features of the three disaster area samples, and the surveys of the wishes of the residents. Therefore, the following three aspects of integration will be investigated hereafter.

(1) In addition to the basic concepts of the general living environment and disaster prevention and mitigation measures, the resettled environments following the Wenchuan earthquake must also 
consider ecology, ethnic culture, geography, economy, paired assistance, public participation, and other aspects $[3,29]$. Through the above analysis, the ecological environment, public participation, economic development, ethnic culture, regional features, and paired assistance mechanisms constitute the focus and concerns in this article.

(2) The three urban areas investigated have similar general evaluation factors, including the living environment, reconstruction, cultural development, and disaster prevention. There are also contrasting evaluation factors; for example, the characteristics of public participation in Dujiangyan are prominent, while Beichuan benefitted from paired assistance, and the ecological carrying capacity of Wenchuan was a key factor. In addition, the same evaluation factor concept, namely, the ethnic culture, among the three samples was different; for instance, while Beichuan is unique, Wenchuan is the embodiment of integration and inclusiveness, and thus, they should be treated differently [41].

(3) A poll of the residents shows that the evaluation factor concepts obtained from the residents in earthquake-affected areas are related mainly to working and living conditions such as roads and other infrastructure elements, living subsidies, health care, education and entertainment, and employment and training [8].

Based on this analysis, this article further examines and clarifies the following corresponding concepts: living environment, comprehensive disaster prevention and mitigation measures, public services infrastructure, construction and the inheritance of the local culture, community organizations, public participation, paired assistance mechanism, protection and promotion of national culture, psychological reconstruction, and economic revival [37]. These 10 aspects contain a great deal of information; however, the existing classification is unclear, and their interrelationships are not sufficiently explicit. Therefore, this article adopts the KJ method (The KJ method is also known as an "affinity diagram", which sorts through complex information on a card according to the language before reorganizing and classifying the information, based on their internal relationships and then integrates them in a merged graph) for a conceptual consolidation.

A survey was conducted among 10 people in different professions within urban planning and architecture (e.g., policy makers, managers, researchers, and experts). Among those surveyed, four were professional associate professors, four were $\mathrm{PhDs}$ or $\mathrm{PhD}$. candidates, and two were managers in urban planning fields with over 15 years of experience. Each expert analyzed the 10 aspects of the content mentioned above and wrote their understanding of the content on cards. After the preliminary reorganization, 74 cards were formed. Under the guidance of the experts' discussion, the cards with similar information were put together during the marshalling phase. For example, the regional characteristics, historical inheritance, national protection, multicultural coexistence and sustainable cultural development all belong to a broader category of cultural reconstruction. Finally, the experts categorized the 74 cards into four groups, namely, the ecological carrying capacity, living environment, life reconstruction, cultural reconstruction, and reconstruction mechanism (Figure 6).

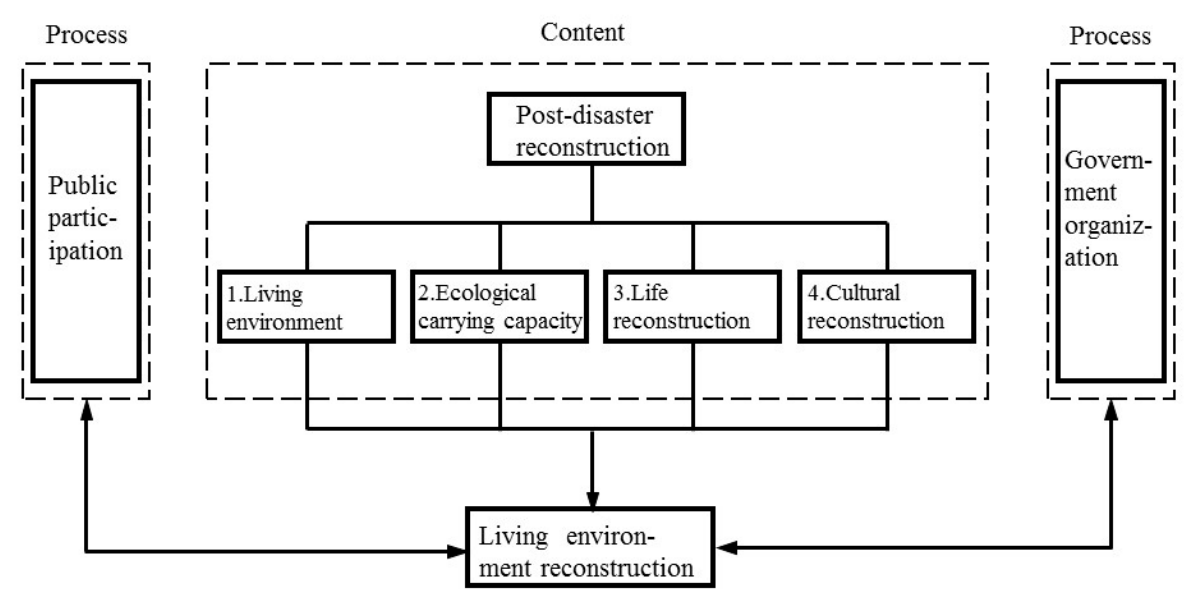

Figure 6. Post-disaster community recovery evaluation concepts and their interrelationships. 


\subsection{Analytical Structuring}

Based on a qualitative analysis of the literature and the practice survey, a summary of the evaluation factors was compiled into the following preliminary evaluation factor set. (1) Ecological carrying capacity: emergency management mechanism, the seismic capacity of lifeline engineering, the formation of autonomous disaster prevention organizations, disaster prevention education, emergency medical rescue, disaster refuge facilities and channels, combined abilities between disasters, and ordinary circumstances, shock resistance. (2) Living environment: housing quality, public service facilities, landscape/greening, location, transportation convenience, apartment layout design, municipal infrastructure, barrier-free design. (3) Life reconstruction: community attraction, psychological reconstruction, neighborhood relationships, life reconstruction of vulnerable groups, public security state. (4) Culture reconstruction: community reconstruction of regional characteristics, history and cultural inheritance, multicultural symbiosis, exchange and integration of urban and rural areas, ethnic characteristics. (5) Reconstruction system: central government, local governments, paired assistance mechanism, non-governmental organizations, community organizations, public participation, media intervention, communication mechanism.

The above-mentioned preliminary summary of the evaluation factors includes a total of 34 evaluation factors spread out among five-factor sets, namely, the ecological carrying capacity, living environment, life reconstruction, culture reconstruction, and reconstruction system. The factor sets were analyzed and constructed using the Delphi method [26,37]. To avoid subjectivity during the construction of the evaluation factors, a semi-structured questionnaire was constructed by utilizing the opinions of 13 separate urban planning experts (i.e., who did not participate in the KJ method), including seven associate professors from related fields, four PhDs and $\mathrm{PhD}$. candidates, and two managers in urban planning with over 15 years of experience. The semi-structured questionnaire consisted of multiple choice and open-ended questions, which encompassed the 34 preliminary evaluation factors divided into five types. The experts were required to make independent choices and indicate the reasons for selecting or abandoning their decisions. After the first round of surveying, the questionnaire results were analyzed, and the experts' forecasts were summarized. A second round of in-depth interviews was conducted for those evaluation factors that diverged or generated controversy, after which the views were integrated again. Finally, a prediction was made related to the research purpose and the characteristics consistent with the natural disaster to a certain degree (Table 2).

Table 2. Primary collection of Class A evaluation factors.

\begin{tabular}{lllll}
\hline $\begin{array}{c}\text { Ecological Carrying } \\
\text { Capacity }\end{array}$ & Living Environment & Life Reconstruction & Regional Culture & $\begin{array}{c}\text { Reconstruction } \\
\text { System }\end{array}$ \\
\hline $\begin{array}{l}\text { Disaster prevention } \\
\text { management and }\end{array}$ & $\begin{array}{l}\text { Housing quality; } \\
\text { public service facilities; }\end{array}$ & $\begin{array}{l}\text { Community } \\
\text { organizations; } \\
\text { community life }\end{array}$ & $\begin{array}{l}\text { Regional characteristic } \\
\text { culture; multi-cultural }\end{array}$ & Government \\
disaster prevention & $\begin{array}{l}\text { landscape/greening; } \\
\text { performance; }\end{array}$ & $\begin{array}{l}\text { sunicipal } \\
\text { relationship; life }\end{array}$ & $\begin{array}{l}\text { symbiosis; historical } \\
\text { and cultural }\end{array}$ & organizations; \\
formation of disaster & infrastructure; & reconstruction of & inheritance; national & participation. \\
self-prevention & transportation & vulnerable groups; & characteristics & \\
measures; public & convenience; location. & psychological & & \\
security state. & & reconstruction. & & \\
\hline
\end{tabular}

Subsequently, through in-depth interviews and open-ended questions, it was discovered that people in earthquake-affected areas are more concerned with employment, cultural development, and emergency evacuation spaces. Consequently, these three evaluation factors were enhanced and the number of options in the questionnaire was increased. During the final analysis, an evaluation index system containing 24 evaluation factors was constructed. Based on the analysis prototype model and the practical research results in addition to an in-depth study of the literature, an evaluation index set of 98 Class B evaluation factors, including the Class A factor set, was created [41]. Then, 
the Delphi method was once again utilized to screen the victims, after which an evaluation factor system containing 50 Class B items was acquired.

\section{Evaluation Index/Mode Construction}

\subsection{Indicator Identification}

To obtain the opinions of additional victims, the 50 Class $B$ evaluation factors were written into the questionnaire to construct a standard questionnaire (for details regarding the standard questionnaire, please see the attachment) for a wide range of samples, and to screen victims during an actual investigation. The probability-proportional-to-size sampling (PPS) method was selected to choose a residential committee or concentration of settlements as the sampling unit. The quota sampling approach was utilized to determine the number of surveys required; for Dujiangyan, 1\% of 33,980 (i.e., houses that required reconstruction following the Wenchuan earthquake) or 350 questionnaires were handed out based on random sampling. A total of 323 questionnaires were valid, with an effective recovery rate of $92.29 \%$. Meanwhile, in-depth interviews were conducted with 35 people. Based on the actual conditions of the affected population, the proportion mentioned above was calculated for the other two sample areas. In Beichuan, 150 questionnaires were issued, with 139 valid responses giving an effective recovery rate of $92.67 \%$, and in-depth interviews were conducted with 15 people. In Wenchuan, 80 questionnaires were issued with 69 valid responses an effective recovery rate of $86.25 \%$, and in-depth interviews were conducted with eight people. The sample towns were visited several times to carry out investigations into the seismic areas at different times. The entire investigation lasted four months, and consisted of door-to-door visits or random sampling, after which more than 60,000 effective messages and 85 variables were acquired.

The residents of the different sample towns evidently focused on different factors, based on a preliminary analysis of the evaluation factors that the residents considered important. By converting the equivalent numbers of the samples for a comparison among the sample areas, the following conclusions were reached.

(1) With regard to the ecological carrying capacity, the three areas showed nearly equivalent concern for disaster prevention management, and education and emergency evacuation spaces. However, Beichuan and Dujiangyan exhibited the highest degree of consideration for the public security state, while Wenchuan demonstrated the opposite, which may have been caused by different reconstruction methods [15]. That is, Beichuan and Dujiangyan mainly relied on paired assistance mechanisms and integrated construction efforts and adopted a modern residential property management mode; meanwhile, Wenchuan adopted methods of reconstructing buildings on the original foundations and self-rebuilding. Compared with 108 and 113 residents in Beichuan and Dujiangyan respectively, only 60 residents in Wenchuan chose "public security situation", because their original living environment and neighborhood relationships were not damaged. Wenchuan residents paid less attention to the disaster prevention performance of facilities, which may have been due to the government's emphasis on infrastructure and public facilities during the reconstruction process, and its focus on environmental governance so that residents can "rest assured" (Figure 7).

(2) With regard to the living environment, the respondents from all three urban areas agreed upon the importance of housing quality, although they were unconcerned with the community location which was difficult for most people to control. However, the Wenchuan residents had opposite opinions on public service facilities and municipal facilities relative to the other two sites; this was again likely due to the disaster features and reconstruction methods [40]. The paired assistance mechanisms and centralized reconstruction of municipal facilities were conveyed through unified planning, and implementation, which the Beichuan and Dujiangyan interviewees agreed did not matter. However, they agreed that the reconstruction of centralized resettlement and the public service facilities could be improved. Meanwhile, more Wenchuan interviewees urgently desired to see improved municipal construction after suffering a large-scale natural disaster (Figure 8). 


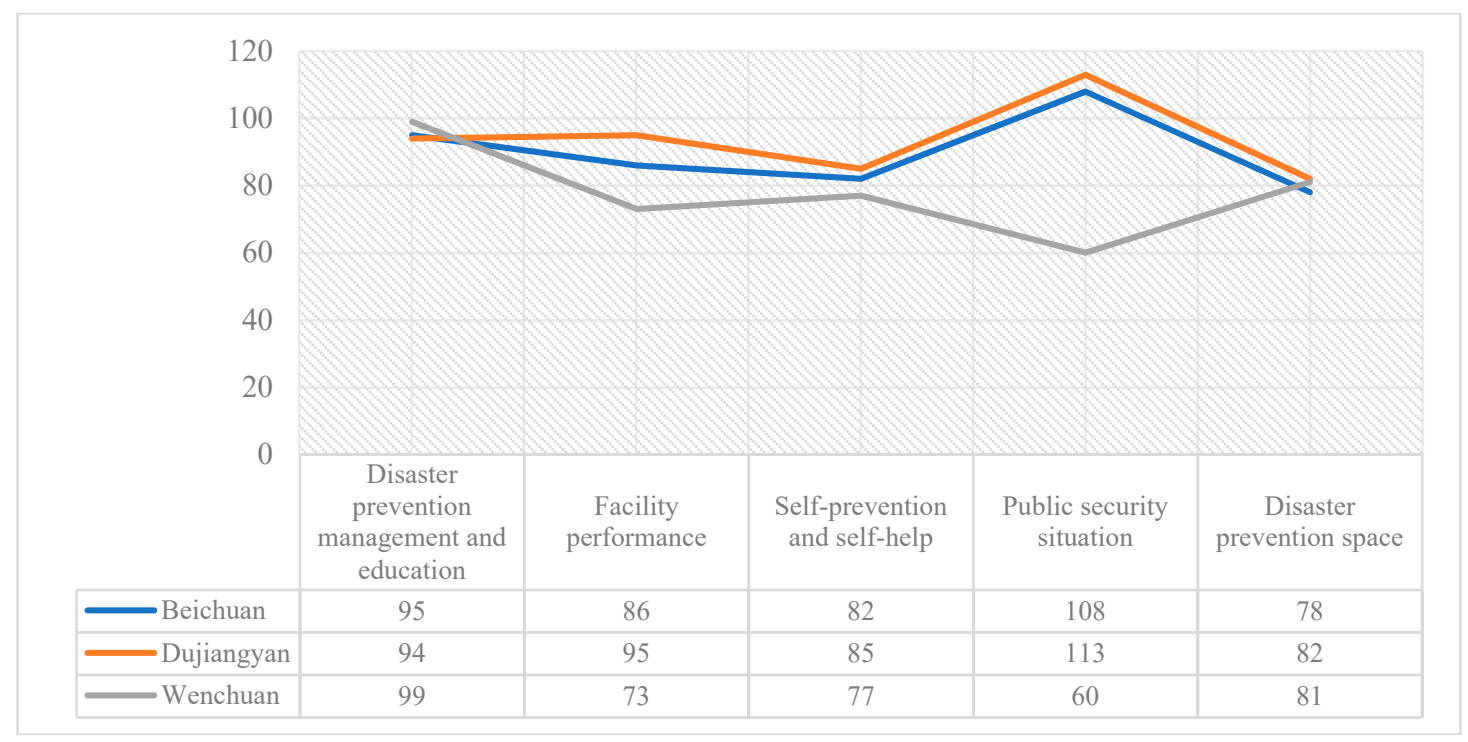

Figure 7. Comparison of the importance of the ecological carrying capacity evaluation factors.

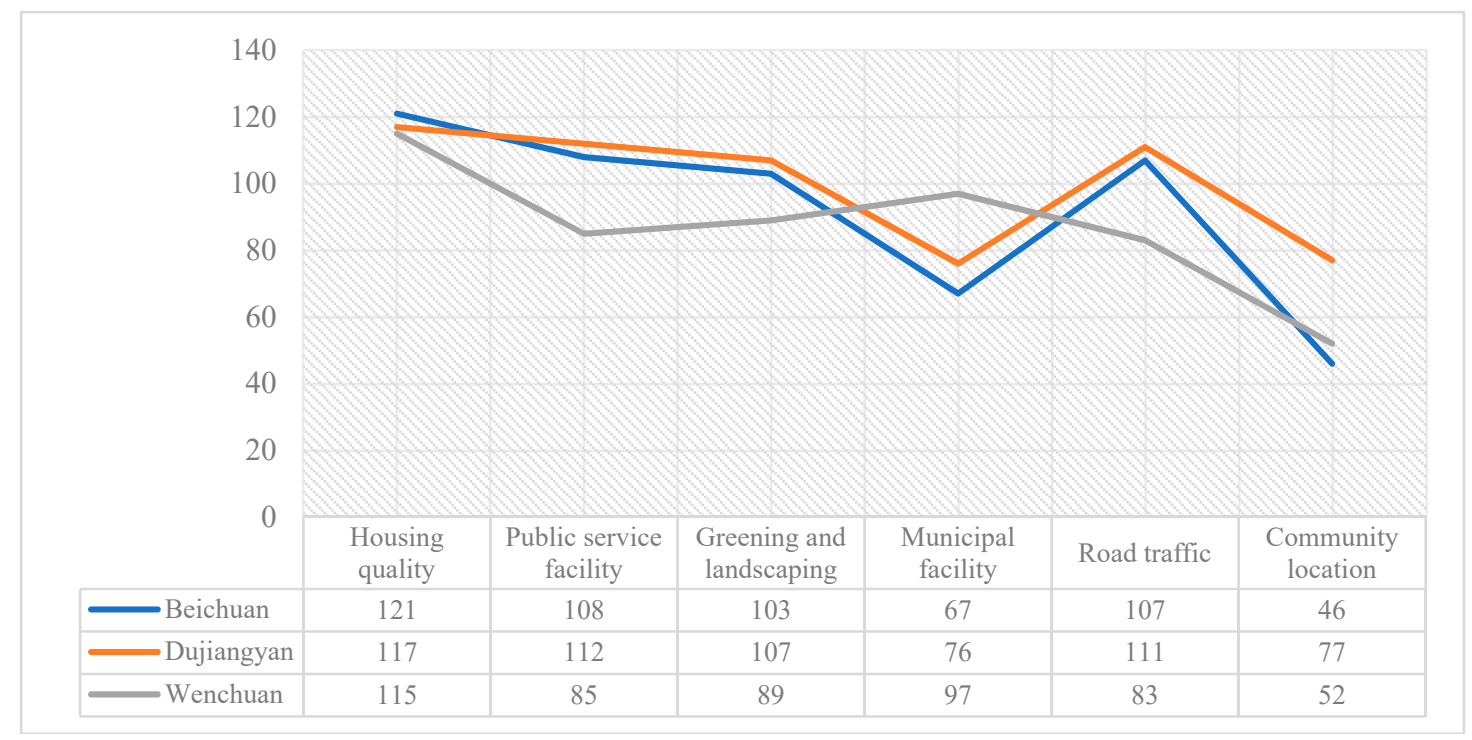

Figure 8. Comparison of the importance of the residential environment evaluation factors.

(3) With regard to life reconstruction, the residents of the three areas consistently emphasized the importance of employment [14]. The interviewed Dujiangyan residents demonstrated an essential balance among the importance of all of the evaluation factors because the residents of Dujiangyan participated substantially in the reconstruction; consequently, they possessed a deeper understanding of life reconstruction, and showed a higher degree of attention toward all of the factors. Beichuan and Wenchuan were almost equally concerned with community cultural activities and community service, indicating that both regions have the desire to improve their standard of living further. However, there was a difference with regard to neighborhood relationships: 96 Beichuan residents took it very seriously, while 42 Wenchuan residents cared very little. Beichuan's equivalent number was more than twice that of Wenchuan. This result is likely also because Beichuan adopted the unified building method; thus, the residents live in mixed habitats where the neighborhood relationships changed gradually [32] (Figure 9). 


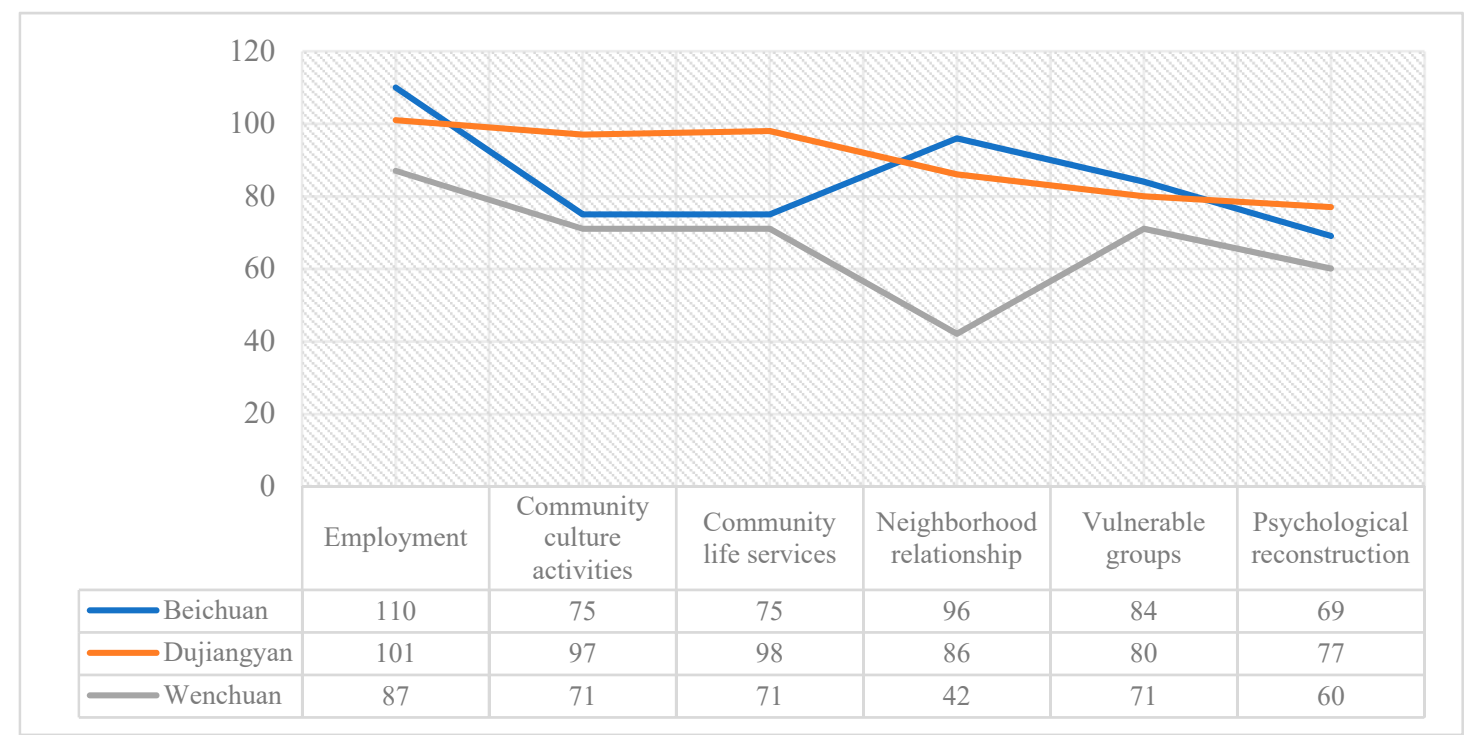

Figure 9. Comparison of the importance of life reconstruction evaluation factors.

(4) With regard to cultural reconstruction, Beichuan and Wenchuan are inhabited by many ethnic minorities, and thus, the research data suggest that the two emphasized the preservation of national culture, and rejected multicultural coexistence. A total of 115 and 119 residents in Beichuan and Wenchuan, respectively, thought that national culture was outstanding, and only 57 and 50 residents, respectively, in the two locations cared about multicultural coexistence. As a historical and culturally ancient city and a famous tourist city, Dujiangyan exhibited cultural tolerance to some degree, although it cared less for the preservation of regional culture than either Beichuan or Wenchuan (Figure 10).

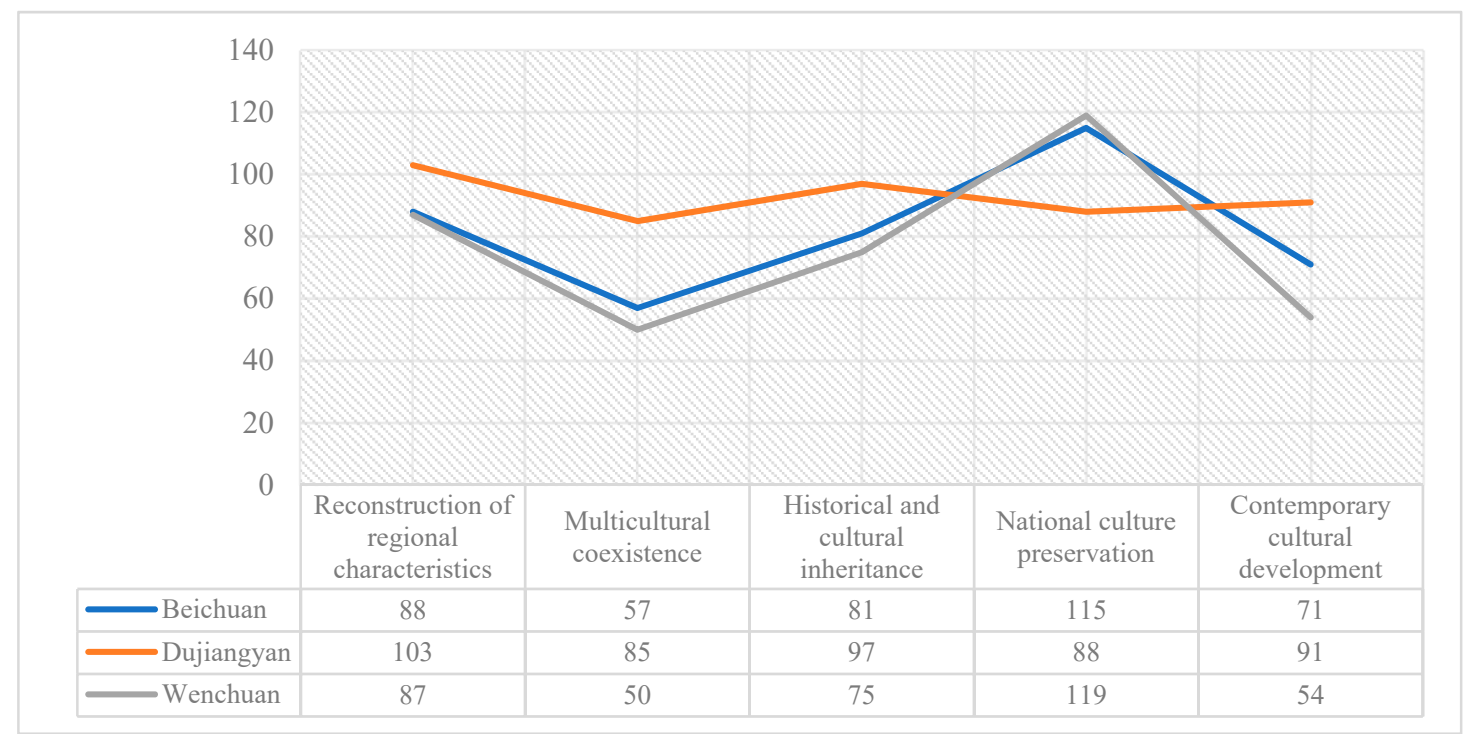

Figure 10. Comparison of the importance of cultural reconstruction evaluation factors.

\subsection{Index Creation}

As discussed above, the three areas demonstrated varying emphases for four sets of Class A evaluation factors; namely, the ecological carrying capacity, living environment, life reconstruction, and cultural reconstruction. These differences indicate that the same factor set was unsuitable for evaluations of the reconstruction states of four different regional reconstructed locations after major disasters. However, the investigation conducted among the three representative urban areas included 
a variety of data, and a factor analysis can further verify and refine evaluation modes with different adaptabilities in the Class B evaluation factors. Factors analysis can be used to extract a few variables, which can clarify the evaluation factor set content and make the application more convenient. Within an index system, the refined factors and suitable indexes of different application objects should be different.

By using the principal component analysis method in the SPSS software, the survey data acquired from the questionnaires answered by the residents of Dujiangyan were analyzed. The extraction of four principal component factors with latent roots that are higher than 1 can explain $83.37 \%$ of the total variance (Table 3). Likewise, a data analysis of the questionnaires filled out by the residents of Beichuan reveals that only two principal component factors have latent roots that are greater than 1; to make the total variance equal to the level of Dujiangyan, the first four principal components were chosen with a cumulative explanatory total variance of $82.64 \%$ (Table 4 ).

Table 3. The total variance of the principal component interpretation of the questionnaires completed by the residents of Dujiangyan.

\begin{tabular}{|c|c|c|c|c|c|c|c|c|c|}
\hline \multirow[b]{2}{*}{ Component } & \multicolumn{3}{|c|}{ Initial Eigenvalues } & \multicolumn{3}{|c|}{ Extracting Square and Loading } & \multicolumn{3}{|c|}{ Rotation Square and Loading } \\
\hline & Summation & $\begin{array}{c}\text { Variance } \\
\%\end{array}$ & $\underset{\%}{\text { Accumulation }}$ & Summation & $\begin{array}{c}\text { Variance } \\
\%\end{array}$ & $\underset{\%}{\text { Accumulation }}$ & Summation & $\begin{array}{c}\text { Variance } \\
\%\end{array}$ & $\begin{array}{c}\underset{\%}{\text { Accumulation }} \\
\%\end{array}$ \\
\hline 1 & 6.785 & 67.846 & 67.846 & 6.785 & 67.846 & 67.846 & 2.565 & 25.653 & 25.653 \\
\hline 2 & 0.634 & 6.335 & 74.181 & 0.634 & 6.335 & 74.181 & 2.475 & 24.754 & 50.407 \\
\hline 3 & 0.500 & 5.005 & 79.186 & 0.500 & 5.005 & 79.186 & 1.819 & 18.186 & 68.593 \\
\hline 4 & 0.418 & 4.179 & 83.365 & 0.418 & 4.179 & 83.365 & 1.477 & 14.773 & 83.365 \\
\hline 5 & 0.372 & 3.717 & 87.082 & & & & & & \\
\hline 6 & 0.352 & 3.516 & 90.598 & & & & & & \\
\hline 7 & 0.310 & 3.102 & 93.700 & & & & & & \\
\hline 8 & 0.247 & 2.473 & 96.173 & & & & & & \\
\hline 9 & 0.212 & 2.124 & 98.298 & & & & & & \\
\hline 10 & 0.170 & 1.702 & 100.00 & & & & & & \\
\hline
\end{tabular}

Table 4. Total variance in the principal component interpretation of the questionnaires completed by the residents of Beichuan.

\begin{tabular}{|c|c|c|c|c|c|c|c|c|c|}
\hline \multirow[b]{2}{*}{ Component } & \multicolumn{3}{|c|}{ Initial Eigenvalues } & \multicolumn{3}{|c|}{ Extracting Square and Loading } & \multicolumn{3}{|c|}{ Rotation Square and Loading } \\
\hline & Summation & $\begin{array}{c}\text { Variance } \\
\%\end{array}$ & Accumulation $\%$ & Summation & $\begin{array}{c}\text { Variance } \\
\%\end{array}$ & $\begin{array}{c}\text { Accumulation } \\
\%\end{array}$ & Summation & $\begin{array}{c}\text { Variance } \\
\%\end{array}$ & $\begin{array}{c}\text { Accumulation } \\
\%\end{array}$ \\
\hline 1 & 6.065 & 60.648 & 60.648 & 6.065 & 60.648 & 60.648 & 3.376 & 33.763 & 33.763 \\
\hline 2 & 1.029 & 10.291 & 70.939 & 1.029 & 10.291 & 70.939 & 1.939 & 19.387 & 53.150 \\
\hline 3 & 0.659 & 6.587 & 77.526 & 0.659 & 6.587 & 77.526 & 1.747 & 17.474 & 70.624 \\
\hline 4 & 0.511 & 5.112 & 82.637 & 0.511 & 5.112 & 82.637 & 1.201 & 12.014 & 82.637 \\
\hline 5 & 0.430 & 4.302 & 86.939 & & & & & & \\
\hline 6 & 0.327 & 3.273 & 90.212 & & & & & & \\
\hline 7 & 0.295 & 2.955 & 93.167 & & & & & & \\
\hline 8 & 0.281 & 2.806 & 95.973 & & & & & & \\
\hline 9 & 0.225 & 2.252 & 98.225 & & & & & & \\
\hline 10 & 0.177 & 1.775 & 100.00 & & & & & & \\
\hline
\end{tabular}

A further analysis of the factor loading and each factor score coefficient matrix showed that the two factors emphasized for the cultural reconstruction factor set by the residents of Dujiangyan and Beichuan differed significantly (Table 5).

The first principal component factors for Dujiangyan were the preservation of national culture, sustainable cultural development, and cultural innovation, all of which had larger absolute load coefficient values that could represent a contemporary culture development factor. The second principal component factors were domestic and international exchanges, and local architectural inheritance, which had larger absolute load coefficient values that indicated multicultural exchanges, and architectural heritage could be a multicultural coexistence factor [25,31]. The third principal component factors were local characteristic landscapes and the preservation of national architecture with larger absolute load coefficients that could represent a regional characteristic construction factor. Finally, the fourth principal component factor was the protection of historical sites, which had a larger absolute load coefficient that could be a history and culture heritage factor. 
Table 5. Comparison of the Class B rotation component matrices for the cultural reconstruction factor set.

\begin{tabular}{lccccccccc}
\hline & \multicolumn{4}{c}{ Dujiangyan } & \multicolumn{4}{c}{ Beichuan } \\
\hline Preservation of national culture & $\mathbf{0 . 7 5 3}$ & 0.257 & 0.202 & 0.417 & 0.302 & $\underline{\mathbf{0 . 7 9 4}}$ & 0.27 & 0.114 \\
Sustainable cultural development & $\mathbf{0 . 6 8 6}$ & 0.419 & 0.399 & 0.13 & $\underline{\mathbf{0 . 6 3}}$ & 0.385 & 0.361 & 0.249 \\
Cultural innovation & $\underline{\mathbf{0 . 6 2 9}}$ & 0.55 & 0.17 & 0.228 & $\underline{\mathbf{0 . 7 9 2}}$ & 0.325 & 0.144 & 0.128 \\
Protection of the historical atmosphere & $\mathbf{0 . 5 7 5}$ & 0.43 & 0.37 & 0.361 & 0.579 & 0.334 & $\underline{\mathbf{0 . 6 3 5}}$ & 0.04 \\
Domestic and international exchanges & $\mathbf{0 . 2 4 7}$ & $\mathbf{0 . 8 3 6}$ & 0.205 & 0.284 & $\underline{\mathbf{0 . 8 4 1}}$ & 0.214 & 0.208 & 0.222 \\
Local architectural inheritance & 0.4 & $\underline{\mathbf{0 . 6 2 7}}$ & 0.356 & 0.256 & 0.347 & 0.176 & 0.277 & $\underline{\mathbf{0 . 8 4 7}}$ \\
Communication between towns and countries & 0.491 & $\mathbf{0 . 6 0 2}$ & 0.364 & 0.082 & $\underline{\mathbf{0 . 6 8 6}}$ & 0.259 & 0.418 & 0.197 \\
Local characteristic landscapes & 0.196 & 0.45 & $\mathbf{0 . 8}$ & 0.18 & $\underline{\mathbf{0 . 7 4 4}}$ & 0.152 & -0.045 & 0.485 \\
Preservation of national architecture & 0.479 & 0.105 & $\underline{\mathbf{0 . 6 7 4}}$ & 0.429 & 0.25 & $\underline{\mathbf{0 . 8 3 9}}$ & 0.206 & 0.139 \\
Protection of historical sites & 0.265 & 0.281 & 0.237 & $\underline{\mathbf{0 . 8 5 7}}$ & 0.114 & 0.27 & $\underline{\mathbf{0 . 8 8 4}}$ & 0.218 \\
\hline
\end{tabular}

Note: The bold and underlining of numbers are the principal components.

The first principal component factors of Beichuan were domestic and international exchanges, and cultural innovation and characteristic local landscapes, all of which had larger absolute load coefficient values that could represent a contemporary culture inheritance factor. The second principal component factors were the preservation of national architecture and the preservation of national culture with larger absolute load coefficients that could be a national culture inheritance factor. The third principal component factors were the protection of historical sites and the protection of the historical atmosphere, both of which had larger absolute load coefficients that could represent the history and culture inheritance factor. Finally, the fourth principal component factor was a local architectural inheritance with a larger absolute load coefficient that could represent a regional characteristic construction factor.

Overall, Beichuan was more concerned with national- and historical-related factors than Dujiangyan and its national, regional, historical, and contemporary culture development evaluation factors were apparently attributable to the different principal components. Meanwhile, Dujiangyan emphasized multicultural exchanges, and its regional and national factors were merged into the reconstruction of regional characteristics. Moreover, an analysis of the component score coefficient matrix showed that the score values for each observed quantity factor could be calculated according to the factor score coefficients and standardized values of the original variables. The results revealed that the component score coefficients were different, suggesting that the corresponding expressions of the principal components were different. Therefore, when using the same factor for an evaluation, Beichuan and Dujiangyan should adopt different factor weights (Table 6). The analysis methods and procedures for Wenchuan were consistent with those of the other two samples. Due to the length of the paper, they will not be repeated, and the conclusions will be provided directly.

Table 6. Comparison of the Class B score coefficient matrixes between Dujiangyan and Beichuan.

\begin{tabular}{|c|c|c|c|c|c|c|c|c|}
\hline \multirow[b]{2}{*}{ Sustainable cultural development } & \multicolumn{4}{|c|}{ Dujiangyan } & \multicolumn{4}{|c|}{ Beichuan } \\
\hline & 0.525 & -0.123 & 0.083 & -0.380 & 0.149 & 0.034 & 0.066 & -0.022 \\
\hline Cultural innovation & 0.393 & 0.182 & -0.354 & -0.113 & 0.398 & 0.011 & -0.153 & -0.256 \\
\hline Preservation of national culture & 0.673 & -0.325 & -0.306 & 0.138 & -0.165 & 0.666 & -0.157 & -0.033 \\
\hline Preservation of national architecture & 0.120 & -0.541 & 0.642 & 0.145 & -0.225 & 0.769 & -0.249 & 0.047 \\
\hline Protection of historical atmosphere & 0.221 & -0.039 & -0.006 & 0.067 & 0.196 & -0.143 & 0.454 & -0.375 \\
\hline Protection of historical sites & -0.383 & -0.005 & -0.203 & 1.111 & -0.276 & -0.167 & 0.810 & 0.104 \\
\hline Domestic and international exchanges & -0.464 & 0.811 & -0.266 & 0.156 & 0.414 & -0.165 & -0.051 & -0.149 \\
\hline Communication between towns and countries & 0.130 & 0.278 & 0.056 & -0.349 & 0.257 & -0.160 & 0.196 & -0.145 \\
\hline Local characteristic landscapes & -0.489 & 0.085 & 0.922 & -0.177 & 0.262 & -0.072 & -0.346 & 0.363 \\
\hline Local architectural inheritance & -0.127 & 0.361 & 0.007 & -0.016 & -0.301 & -0.055 & 0.002 & 1.077 \\
\hline
\end{tabular}

Similarly, a factor analysis was adopted to reduce the dimensionality and then update and reconstruct the four types of level Class B evaluation factor sets, to ultimately obtain three evaluation factor sets comprising the same structure and similar content, but with different details. The three-evaluation factor set modes are known as Dujiangyan mode, Beichuan mode, and Wenchuan mode, and each of the three modes had different characteristics and applicable scopes (Table 7). 
Table 7. Construction factor sets of the adaptive evaluation index system for urban community recovery after disasters.

\begin{tabular}{|c|c|c|c|c|}
\hline \multirow{2}{*}{ Aim Layer } & \multirow{2}{*}{ Criterion Layer } & \multicolumn{2}{|r|}{ Factor Layer } & \multirow{2}{*}{ Program Layer } \\
\hline & & Class A Layer & Class B Layer & \\
\hline \multirow{5}{*}{$\begin{array}{l}\text { Evaluation factor set of } \\
\text { community recovery in } \\
\text { cities and towns of } \\
\text { Wenchuan } \\
\text { earthquake-stricken } \\
\text { areas }\end{array}$} & $\begin{array}{l}\text { Ecological carrying } \\
\text { capacity }\end{array}$ & $\begin{array}{l}\text { Disaster prevention } \\
\text { management and } \\
\text { education, facility } \\
\text { disaster prevention } \\
\text { performance, disaster } \\
\text { self-prevention and } \\
\text { self-help, public security } \\
\text { situation, emergency } \\
\text { evacuation spaces }\end{array}$ & $\begin{array}{l}\text { Disaster prevention laws, simulation } \\
\text { exercises, earthquake emergency } \\
\text { plans, seismic performance facilities, } \\
\text { building seismic intensity, disaster } \\
\text { prevention and residential self-help } \\
\text { awareness, community } \\
\text { self-prevention organizations, } \\
\text { community security, property } \\
\text { management, escape routes, special } \\
\text { places for disaster prevention, per } \\
\text { capita effective evacuation areas }\end{array}$ & \multirow{5}{*}{$\begin{array}{l}\text { 1. Dujiangyan mode } \\
\text { 2. Beichuan mode } \\
\text { 3.Wenchuan mode }\end{array}$} \\
\hline & $\begin{array}{l}\text { Living } \\
\text { environment }\end{array}$ & $\begin{array}{l}\text { Housing quality, public } \\
\text { service facilities, } \\
\text { greening and } \\
\text { landscaping, municipal } \\
\text { facilities, road traffic, } \\
\text { community location }\end{array}$ & $\begin{array}{l}\text { Construction quality, apartment } \\
\text { layout design, residential distance, } \\
\text { convenient service facilities, health } \\
\text { care facilities, educational facilities, } \\
\text { pro-green/pro-water, community } \\
\text { public spaces, community } \\
\text { environmental landscape design, } \\
\text { municipal facilities, fire safety } \\
\text { facilities, travel convenience, road } \\
\text { system integrity, community planning } \\
\text { and layout, mature degree of the } \\
\text { surrounding supporting facilities }\end{array}$ & \\
\hline & Life reconstruction & $\begin{array}{l}\text { Employment, } \\
\text { community culture } \\
\text { activities, community } \\
\text { life services, } \\
\text { neighborhood } \\
\text { relationships, vulnerable } \\
\text { groups, psychological } \\
\text { reconstruction }\end{array}$ & $\begin{array}{l}\text { Employment opportunities, } \\
\text { employment information publishing, } \\
\text { employment training, community } \\
\text { cultural atmosphere, community } \\
\text { activities, community organizations, } \\
\text { community service, exchange of } \\
\text { neighborhood residents, behavior } \\
\text { civilization, barrier-free design, basic } \\
\text { protection of vulnerable groups, } \\
\text { psychological resilience, } \\
\text { psychological relief organizations }\end{array}$ & \\
\hline & $\begin{array}{l}\text { Cultural } \\
\text { reconstruction }\end{array}$ & $\begin{array}{l}\text { Regional characteristic } \\
\text { construction, } \\
\text { multicultural } \\
\text { coexistence, historical } \\
\text { and cultural inheritance, } \\
\text { protection of national } \\
\text { culture, development of } \\
\text { contemporary culture }\end{array}$ & $\begin{array}{l}\text { Inheritance of local architectural style, } \\
\text { local characteristic landscapes, urban } \\
\text { and rural exchanges, } \\
\text { domestic/international exchanges, } \\
\text { protection of historical sites, } \\
\text { protection of historical atmosphere, } \\
\text { preservation of ethnic architecture, } \\
\text { preservation of ethnic culture, } \\
\text { cultural innovation, sustainable } \\
\text { cultural development }\end{array}$ & \\
\hline & $\begin{array}{l}\text { Reconstruction } \\
\text { mechanism }\end{array}$ & $\begin{array}{l}\text { Governmental } \\
\text { organizations, public } \\
\text { participation }\end{array}$ & & \\
\hline
\end{tabular}

\subsection{Summary}

According to the above research, the information obtained from the same standard questionnaire had specific differences, and the focus of the victims was different, and the degree of attention was different. Therefore, even under the same circumstances of post-disaster reconstruction, the evaluation index system should be used differently in the evaluation of different living environments. The following are applicable scopes of different modes:

(1) Dujiangyan mode: suitable for large-scale cities and towns with complex urban community recovery practices where self-building is the primary method, involving a number of individuals or related departments for local protection demands. (2) Beichuan mode: applicable to severely affected seismic areas with distinctive national characteristics; the proportion of reconstruction is large and even requires overall relocation and reconstruction schemes relying mainly upon one unified building scheme or a paired assistance mechanism. (3) Wenchuan mode: applicable to a more complex ecological environment with a strong sense of national inclusiveness, more frequent secondary disasters and relatively balanced reconstruction methods; namely, unified construction, paired assistance reconstruction, and self-reconstruction. Therefore, any reconstruction practice that is 
similar to any of these three modes can directly learn from the corresponding evaluation factor set to rapidly form a system and evaluate community recovery, thereby hastening evaluation, simplifying operations and making the operation more economical.

In the current study, these three models only establish the factor set. If the evaluation index system is to be established, the value of factor should be assigned through quantitative research. Moreover, these evaluation index systems can be applied to a comprehensive assessment of post-disaster reconstruction. In Japan's post-disaster reconstruction assessment, the government has seized critical issues at the macro-level, adhered to tracking, monitoring, and evaluation for more than a decade, and established a vast database, providing valuable reference materials for post-disaster recovery, urban planning, and urban renewal.

\section{Conclusions}

This article analyzed existing comprehensive evaluation theories and methods, examined actual disaster situations, and provided an in-depth investigation of residential living situations in earthquake-affected areas. Through data analysis and technological support, a focus and vision for the future were eventually formulated through a set of evaluation factors for the reconstructed environments of cities and towns in the areas affected by the Wenchuan earthquake. The following conclusions can be drawn.

(1) The post-disaster reconstruction of Dujiangyan is characterized by fully guaranteeing the residents' right to self-reconstruction. The main focus of the people was on the fairness of public policies, distribution policies, and processes. The study demonstrates the enthusiasm of the people in the disaster areas of Dujiangyan for public participation. The reconstruction of Beichuan has taken place in a new location, but the separation of populations at different levels has brought about the problem of urban spatial segregation. At the same time, the investment in urban land use is extremely large, but the utilization efficiency is not so high. In order to open up shelters for the old city, Wenchuan demolished a certain number of dangerous houses, and residents moved to the new city, far from the old city. The optimization and adjustment of the urban spatial structure after the disaster has brought about the reconstruction of social organizations to some extent, and it takes time for communities to integrate.

(2) In this study, through a questionnaire survey and in-depth interviews, the most essential factors emphasized by the victims were selected, beginning with the needs of the people living in the earthquake-affected areas. Combined with a quantitative approach (i.e., principal component analysis) that gave further verification, the homogeneities and heterogeneities among the three samples areas were refined to complete the updating of the evaluation factor set. From the field investigation and in-depth study of the three sample areas (i.e., Dujiangyan, Beichuan and Wenchuan), it can be seen that people in different areas evidently consider different evaluation factors to be important; consequently, the emphasis on a particular evaluation factor varies, and the correlations between different evaluation factors are also different. The result is that the same set of evaluation factors is unsuitable for satisfying the needs of different evaluation objects.

(3) The above method of evaluation of the reconstruction of the living environments of Dujiangyan City, and Yongchang Town and Weizhou Town following the Wenchuan earthquake is suitable for a case analysis of any similarly affected city or town. The reconstruction efforts conducted in other areas of Sichuan after the Wenchuan earthquake varied among the cities and towns. Some of these are similar to the study areas, while others are unique. For example, before the Wenchuan earthquake, Shifang, Mianzhu, and Pengzhou were industrial cities; however, the earthquake caused significant damage to the industrial base, and thus, economic recovery problems are prominent in their reconstruction scheme. Beichuan was the only town that was entirely relocated, whose paired assistance mechanism was obvious. Though they were not relocated, Yinxiu, Qingchuan, and Pingwu also belong to this type, and they are characterized by a complex ecological environment, severe environmental damage, and strong disaster prevention measures. In future, case analyses and 
detailed evaluations of these other areas could provide additional scientific guidance for post-disaster community recovery practices in different areas.

The limitation of the study is that the article only compared the three urban areas with cross-sectional research, but did not compare each town with longitudinal research. If further studies can make a longitudinal comparison of urban post-disaster reconstruction planning expectations, reconstruction process, development and change, current situation, and future prediction within a particular time dimension, there would be a deeper understanding of different reconstruction modes, which would be helpful to evaluate the current situation and to prepare for the future.

Supplementary Materials: The following are available at http://www.mdpi.com/2071-1050/10/11/4115/s1.

Author Contributions: The individual contribution and responsibilities of the authors are listed as follows: M.X. proposed and designed the research, collected the data and wrote the paper; W.Z. conducted the literature review, gave some comments, and helped to edit the manuscript; J.C. analyzed the data and proofread the manuscript. All authors reviewed and approved the final manuscript.

Funding: The research for this article was supported by the National Natural Science Foundation of China [Grant Nos. 51408514, 51878558].

Acknowledgments: This work was made possible by contributions from residents in Dujiangyan, Beichuan, and Wenchuan. The residents provided significant help in the questionnaire survey. The authors express their sincere appreciation here for their generous cooperation and valuable input. The authors would like to thank the anonymous reviewers for their constructive comments regarding this article.

Conflicts of Interest: The authors declare that there are no potential conflicts of interest.

\section{References}

1. UNISDR. Sendai Framework for Disaster Risk Reduction 2015-2030. In Proceedings of the 3rd United Nations World Conference on DRR, UNISDR, Sendai, Japan, 14-18 March 2015.

2. Blair, M.L.; Spangle, W.E. Seismic Safety and Land-Use Planning-SELECTED Examples from California; US Government Printing Office: For sale by the Superintendent of Documents, Government Printing Office: Washington, DC, USA, 1979.

3. Smith, G.P.; Wenger, D. Sustainable Disaster Recovery: Operationalizing an Existing Agenda. In Handbook of Disaster Research; Rodriguez, E.L.Q.H., Dynes, R., Eds.; Springer: New York, NY, USA, 2007; pp. $234-257$.

4. Applied Technology Council; Rojahn, C.; Shapiro, D.; Moehle, J. NEHRP Guidelines for the Seismic Rehabilitation of Buildings; Federal Emergency Management Agency: Washington, DC, USA, 1997; Volume 1.

5. Zhang, J.; Zhou, C.; Xu, K.; Watanabe, M. Flood disaster monitoring and evaluation in China. Glob. Environ. Chang. Part B Environ. Hazards 2002, 4, 33-43. [CrossRef]

6. Berke, P.; Cooper, J.; Aminto, M.; Grabich, S.; Horney, J. Adaptive planning for disaster recovery and resiliency: An evaluation of 87 local recovery plans in eight states. J. Am. Plan. Assoc. 2014, 80, 310-323. [CrossRef]

7. Wang, Y.; Li, Z.; Tang, Z.; Zeng, G. A GIS-based spatial multi-criteria approach for flood risk assessment in the Dongting Lake Region, Hunan, Central China. Water Resour. Manag. 2011, 25, 3465-3484. [CrossRef]

8. Hashemi-Parast, S.O.; Yamazaki, F.; Liu, W. Monitoring and evaluation of the urban reconstruction process in Bam, Iran, after the 2003 M w 6.6 earthquake. Nat. Hazards 2017, 85, 197-213. [CrossRef]

9. Folke, C.; Carpenter, S.; Elmqvist, T.; Gunderson, L.; Holling, C.S.; Walker, B. Resilience and sustainable development: Building adaptive capacity in a world of transformations. AMBIO A J. Hum. Environ. 2002, 31, 437-440. [CrossRef]

10. Tweed, F.; Walker, G. Some lessons for resilience from the 2011 multi-disaster in Japan. Local Environ. 2011, 16, 937-942. [CrossRef]

11. Kılc1, F.; Kara, B.Y.; Bozkaya, B. Locating temporary shelter areas after an earthquake: A case for Turkey. Eur. J. Oper. Res. 2015, 243, 323-332. [CrossRef]

12. Folke, C.; Carpenter, S.R.; Walker, B.; Scheffer, M.; Chapin, T.; Rockström, J. Resilience thinking: Integrating resilience, adaptability and transformability. Ecol. Soc. 2010, 15, 20. [CrossRef] 
13. Song, Y.; Li, C.; Olshansky, R.; Zhang, Y.; Xiao, Y. Are we planning for sustainable disaster recovery? Evaluating recovery plans after the Wenchuan earthquake. J. Environ. Plan. Manag. 2017, 60, 2192-2216. [CrossRef]

14. Smith, N.; Brown, C.; McDonald, G.; Ayers, M.; Kipp, R.; Saunders, W. Challenges and opportunities for economic evaluation of disaster risk decisions. Econ. Disasters Clim. Chang. 2017, 1, 111-120. [CrossRef]

15. Li, G.-P.; Peng, S.-Q.; Yang, L. The Efficiency Evaluation of Post-disaster Reconstruction Policy-From the Angle of Sichuan Earthquake-afflicted People. Soft Sci. 2013, 8, 28. (In Chinese)

16. Gallopín, C.G. Linkages between vulnerability, resilience, and adaptive capacity. Glob. Environ. Chang. 2006, 16, 293-303. [CrossRef]

17. UNISDR. How to Make Cities More Resilient: A Handbook for Local Government Leaders; The United Nations International Strategy for Disaster Reduction Geneva: Geneva, Switzerland, 2012.

18. Committee, D.A. Principles for Evaluation of Development Assistance; Organization for Economic Co-operation and Development: Paris, France, 1991.

19. Clark, M.; Sartorius, R.; Bamberger, M. Monitoring and Evaluation: Some Tools, Methods and Approaches; The World Bank: Washington, DC, USA, 2004.

20. Bolin, R.C. Household and Community Recovery after Earthquakes; Institute of Behavioral Science, University of Colorado: St. Boulder, CO, USA, 1994; ISBN 1877943118.

21. Istijono, B.; Ophiyandri, T.; Chairisna, D.; Tadzkia, A. Communities' Satisfaction towards Housing Rehabilitation and Reconstruction Program after 30 September 2009, Earthquake in West Sumatra. J. Constr. Eng. 2016, 2016, 1-8. [CrossRef]

22. Dikmen, N.; Elias-Ozkan, S.T. Housing after disaster: A post occupancy evaluation of a reconstruction project. Int. J. Disaster Risk Reduct. 2016, 19, 167-178. [CrossRef]

23. Zhao, Y. Post-disaster Planning and Reconstruction of Property Rights. Urban Stud. 2008, 4, 4. (In Chinese)

24. Dunford, M.; Li, L. Earthquake reconstruction in Wenchuan: Assessing the state overall plan and addressing the 'forgotten phase'. Appl. Geogr. 2011, 31, 998-1009. [CrossRef]

25. Chen, S.; Mao, M.; Liu, Z. The Empirical Study on the Post-Disaster Reconstruction Capacity and Its Performance: County-level Government in Wenchuan Earthquake as an Example. China Popul. Resour. Environ. 2014, 24, 156-161. (In Chinese)

26. Jordan, E.; Javernick-Will, A.; Amadei, B. Post-disaster reconstruction: Lessons from Nagapattinam district, India. Dev. Pract. 2015, 25, 518-534. [CrossRef]

27. UNISDR. Hyogo framework for action 2005-2015: Building the resilience of nations and communities to disasters. In Extract from the Final Report of the World Conference on Disaster Reduction (A/CONF. 206/6); The United Nations International Strategy for Disaster Reduction Geneva: Geneva, Switzerland, 2005.

28. Qiu, B. Ecological City Outline for Post-Disaster Reconstruction. Urban Stud. 2008, 3, 11-17. (In Chinese)

29. Chen-hai, Z.; Zeng, Q. A Study of Evaluation Index System of Result-oriented Social Work-The Case Study of Post-disaster Reconstruction Services in Dujiangyan. J. Northwest Norm. Univ. (Soc. Sci.) 2009, 3, 16. (In Chinese)

30. Lin, L.; Wang, Y.; Liu, T. Perception of recovery of households affected by 2008 Wenchuan earthquake: A structural equation model. PLoS ONE 2017, 12, e0183631. [CrossRef] [PubMed]

31. Wang, Z.; Xu, J. Association between resilience and quality of life in Wenchuan Earthquake Shidu parents: The mediating role of social support. Community Ment. Health J. 2017, 53, 859-863. [CrossRef] [PubMed]

32. Park, A.; Wang, S. Benefiting from Disaster? Public and Private Responses to the Wenchuan Earthquake. World Dev. 2017, 94, 38-50. [CrossRef]

33. Zhong, K.; Lu, X. Exploring the administrative mechanism of China's Paired Assistance to Disaster Affected Areas programme. Disasters 2018, 42, 590-612. [CrossRef] [PubMed]

34. Zhao, W.; Yang, J. Preliminary Study on Evaluation System of Housing Environment in Earthquake Stricken Area of Wenchuan. Sichuan Build. Sci. 2009, 35, 168-170. (In Chinese)

35. Yang, B.; Jahan, I. Comprehensive Assessment for Post-Disaster Recovery Process in a Tourist Town. Sustainability 2018, 10, 1842. [CrossRef]

36. Vogdopoulou, E. Master Plan Evaluation. A Tool to Enhance Successful Urban Regeneration. Regent Quarter Case Study; UCL (University College London): London, UK, 2006. 
37. Cao, W.; Xiao, H. Establishment and application of comprehensive evaluation system for the ability of post-disaster recovery and reconstruction. In Proceedings of the International Conference on Information Systems for Crisis Response and Management (ISCRAM), Lisbon, Portugal, 8-11 May 2011.

38. Dissanayake, D. Evaluation of Stakeholder Satisfaction in Disaster Reconstruction Process: Case of Tsunami Damaged Schools in Sri Lanka; Department of Building Economics, University of Moratuwa Sri Lanka: Colombo, Sri Lanka, 2011.

39. Lizarralde, G. Organizational design, performance and evaluation of post-disaster reconstruction projects. In Proceedings of the First International Conference on Post-Disaster Reconstruction: Improving Post-Disaster Reconstruction in Developing Countries, Coventry, UK, 22-23 April 2002.

40. Liu, Q.; Teng, Y. Research of sustainable development evaluation model of major natural disasters post-disaster reconstruction. J. Disaster Prev. Reduct. 2012, 3, 2. (In Chinese)

41. Hemphill, L.; Berry, J.; McGreal, S. An indicator-based approach to measuring sustainable urban regeneration performance: Part 1, conceptual foundations and methodological framework. Urban Stud. 2004, 41, 725-755. [CrossRef]

42. Sun, C.; Bi, R. Study on disaster reconstruction project performance evaluation based on fuzzy analytic network process. In Proceedings of the 2010 International Symposium on Computer, Communication, Control and Automation (3CA), Tainan, Taiwan, 5-7 May 2010.

43. Tong, C. Review on environmental indicator research. Res. Environ. Sci. 2000, 13, 53-55. (In Chinese)

44. Xiang, M.M.; Li, X.N.; Fu, J.L. Research on the Evaluation Elements of Post-Disaster Reconstruction. Appl. Mech. Mater. 2012, 174-177, 3611-3614. [CrossRef]

45. Rall, E.L.; Haase, D. Creative intervention in a dynamic city: A sustainability assessment of an interim use strategy for brownfields in Leipzig, Germany. Landsc. Urban Plan. 2011, 100, 189-201. [CrossRef]

46. Liu, Y.; Zhao, H. Study on comprehensive evaluation index system of urban disaster reduction management in China. J. Nat. Disasters 1999, 8, 61-66. (In Chinese)

47. Chen, S. A study on the evaluation of the government's emergency response capacity in the five major disaster areas of the Wenchuan earthquake-Based on the perspective of evaluation of the affected people. Public Adm. Rev. 2009, 1, 112-131. (In Chinese)

48. Zhang, Q.; Gao, Y.F.; Gao, N.; Guo, J.S.; Wang, B.K. Construction of evaluation index system of urban community earthquake emergency response capability. Disasters 2009, 24, 133-136. (In Chinese)

49. Liu, S.; Liu, B. Study on evaluation system of sustainable development of urban residential environment. Urban Plan. J. 1999, 5, 35-37. (In Chinese)

50. Li, W.; Ye, X. Evaluation of urban living environment-Taking hangzhou city as an example. Econ. Geogr. 1999, 19, 38-43. (In Chinese)

51. Tian, L.; Shen, T. Evaluation of plan implementation in the transitional China: A case of Guangzhou city master plan. Cities 2011, 28, 11-27. [CrossRef]

52. Xiao, J.; Shen, Y.J.; Ge, J.F.; Tateishi, R.; Tang, C.; Liang, Y.Q.; Huang, Z.Y. Evaluating urban expansion and land use change in Shijiazhuang, China, by using GIS and remote sensing. Landsc. Urban Plan. J. 2006, 75, 69-80. [CrossRef]

53. Coombes, M.; Wong, C. Methodological steps in the development of multivariate indexes for urban and regional policy analysis. Environ. Plan. A 1994, 26, 1297-1316. [CrossRef]

54. Wollebæk, D.; Selle, P. Participation and Social Capital Formation: Norway in a Comparative Perspective 1. Scand. Political Stud. 2003, 26, 67-91. [CrossRef]

55. Burby, R.J. Cooperating with Nature: Confronting Natural Hazards with Land-Use Planning for Sustainable Communities; Joseph Henry Press: Washington, DC, USA, 1998; ISBN 0309063620.

(C) 2018 by the authors. Licensee MDPI, Basel, Switzerland. This article is an open access article distributed under the terms and conditions of the Creative Commons Attribution (CC BY) license (http:/ / creativecommons.org/licenses/by/4.0/). 